Portland State University

PDXScholar

\title{
Second-generation International Space Station Total Organic Carbon Analyzer Verification Testing and On-orbit Performance Results
}

\author{
Nicole L. Bentley \\ Evan A. Thomas \\ Portland State University \\ Michael Van Wie \\ Chad Morrison
}

Follow this and additional works at: https://pdxscholar.library.pdx.edu/mengin_fac

Part of the Systems Engineering Commons

Let us know how access to this document benefits you.

\section{Citation Details}

Bentley, N., Thomas, E., Van Wie, M., Morrison, C., Stinson, R., Second Generation International Space Station (ISS) Total Organic Carbon Analyzer (TOCA) Verification Testing and On-Orbit Performance Results, International Conference on Environmental Systems, Narcelona, 2010. DOI: 10.2514/6.2010-6043

This Article is brought to you for free and open access. It has been accepted for inclusion in Mechanical and Materials Engineering Faculty Publications and Presentations by an authorized administrator of PDXScholar. Please contact us if we can make this document more accessible: pdxscholar@pdx.edu. 


\title{
Second-generation International Space Station Total Organic Carbon Analyzer Verification Testing and On-orbit Performance Results
}

\author{
Nicole L. Bentley ${ }^{1}$ and Evan A. Thomas, Ph.D. ${ }^{2}$ \\ NASA-Johnson Space Center, Houston, Texas 77058 \\ Michael Van Wie, Ph.D., ${ }^{3}$ and Chad Morrison ${ }^{4}$ \\ Wyle, Integrated Science and Engineering Group, Houston, Texas 77058 \\ and \\ Richard G. Stinson ${ }^{5}$ \\ Lockheed Martin Mission Services, Houston, Texas 77058
}

\begin{abstract}
The International Space Station (ISS) total organic carbon analyzer (TOCA) is designed to autonomously assess recovered water quality by providing an indication of total organic carbon (TOC). The current TOCA has been on the ISS since November 2008. Functional checkout and operations revealed complex operating considerations. Specifically, failure of the hydrogen $\left(\mathrm{H}_{2}\right)$ catalyst resulted in development of an innovative oxidation analysis method. This method reduces activation time and limits the $\mathbf{H}_{2}$ produced during analysis, while retaining the ability to indicate TOC concentrations within $25 \%$ accuracy. Subsequent testing and comparison to archived samples returned from the station and tested on the ground yield high confidence in this method, and in the quality of the recovered water.
\end{abstract}

\section{Nomenclature}

$\begin{array}{ll}\text { A/CO: } & \text { activation and checkout } \\ \text { BDD: } & \text { boron doped diamond } \\ \mathrm{CO}_{2}: & \text { carbon dioxide } \\ \text { COTS: } & \text { commercial off-the-shelf } \\ \text { EDU: } & \text { engineering development unit } \\ \text { GIDEP: } & \text { government-industry data exchange program } \\ \text { GLS: } & \text { gas-liquid-separator } \\ \mathrm{H}_{2}: & \text { hydrogen } \\ \mathrm{H}_{3} \mathrm{PO}_{4}: & \text { phosphoric acid } \\ \text { ISS: } & \text { International Space Station } \\ \mathrm{IR}: & \text { infrared } \\ \mathrm{KHP}: & \text { potassium hydrogen phthalate } \\ \mathrm{L}: & \text { liter } \\ \mathrm{mA}: & \text { milliamp } \\ \mathrm{MDL}: & \text { method detection limit } \\ \mathrm{N}_{2}: & \text { nitrogen } \\ \mathrm{ND}^{\mathrm{IR}}: & \text { nondispersive-infrared } \\ (\mathrm{NH})_{2} \mathrm{~S}_{2} \mathrm{O}_{8}: & \text { ammonium persulfate } \\ \mathrm{O}_{2}: & \text { oxygen } \\ \mathrm{ORU}: & \text { on-orbit replaceable unit }\end{array}$

${ }^{1}$ Project Manager, Life Support and Habitability Systems Branch, Mailcode EC3

${ }^{2}$ Deputy Project Manager, Life Support and Habitability Systems Branch, Mailcode EC3, AIAA Grade MB

${ }^{3}$ Project Engineer, Wyle, Integrated Science and Engineering Group, Houston, Texas.

${ }^{4}$ Project Engineer, Wyle, Integrated Science and Engineering Group, Houston, Texas.

${ }^{5}$ Project Engineer, Bioastronautics Systems Engineering, Lockheed Martin Mission Services, Houston, Texas. 
PFU: $\quad$ protoflight unit

PWD: $\quad$ portable water dispenser

TC: $\quad$ total carbon

TIC: $\quad$ total inorganic carbon

TOC: total organic compoundcarbon

TOCA: total organic compoundcarbon analyzer

$\mu \mathrm{g}: \quad$ micrograms

USB: universal serial bus

VCA: volume compensation assembly

WAFAL: Water and Food Analysis Laboratory

WPA: water processing assembly

\section{Introduction}

Tn support of a crew of six on board the International Space Station (ISS), wastewater and urine is reclaimed and Ireprocessed into potable water. The ISS regenerative water processing assembly (WPA) purifies wastewater into potable water for consumption and oxygen $\left(\mathrm{O}_{2}\right)$ generation on station. The total organic carbon analyzer (TOCA) takes samples of WPA water and analyzes for the presence of total organic carbon (TOC). Measuring TOC in the water provides a general assessment of water quality by indicating the potential presence of hazardous organic load. Low TOC indicates the water processor is likely functioning properly. The WPA, which also contains conductivity sensors to monitor water quality, directs re-processing if water quality parameters are not met. These conductivity sensors are the first and second controls for water quality on ISS, and TOCA serves as the third control to out-ofspecification potable water. The TOCA was designed to be a stand-alone, redeployable piece of hardware that performs off-line sampling of regenerated potable water from the WPA.

TOCA is located close to the Water Recovery System (WRS) rack to enable direct sampling from the WPA. TOCA can also receive samples via a sample bag, which is normally filled from the potable water dispenser (PWD) on orbit. Several principles of TOC analysis are listed below:

- Total carbon $(\mathrm{TC})=$ total inorganic carbon (TIC) + TOC

- TIC interferes with the direct measurement of TOC and must be removed prior to measuring TOC

- TOCA converts and removes TIC by creating a $\mathrm{pH}$ shift with a slightly acidic buffer that forces inorganic carbon species into carbon dioxide $\left(\mathrm{CO}_{2}\right)$ gas

- TOCA oxidizes organic carbon species remaining in the sample water to $\mathrm{CO}_{2}$ gas

- TOCA-produced $\mathrm{CO}_{2}$ gas is measured using a very precise infrared $\mathrm{CO}_{2}$ detector

Terrestrially, TOC analyzers employ various methods to determine TOC. Typically, ground-based units involve wet chemistry techniques that use hazardous reagents or high-temperature combustion. The first-generation ${ }^{1}$ ISS TOC $^{2}$ analyzer employed phosphoric acid $\left(\mathrm{H}_{3} \mathrm{PO}_{4}\right)$ and ammonium persulfate $\left(\left(\mathrm{NH}_{4}\right)_{2} \mathrm{~S}_{2} \mathrm{O}_{8}\right)$, both designated as toxicity level 2 chemicals. Use of these reagents resulted in design complexity and required two verifiable levels of containment. The lessons learned from the first-generation TOCA resulted in the ISS Program requesting that the new unit not use hazardous liquid reagents.

The analytical range also posed a challenge. The ISS Program required a 1,000 to $25,000 \mu \mathrm{g} / \mathrm{L}$ range with an accuracy of $\pm 25 \%$ for TOC. The need for a large analytical range was driven by various international supplies of potable water. The go/no-go decision on water potability is $3,000 \mu \mathrm{g} / \mathrm{L}$ for WPA-supplied water and 20,000 $\mu \mathrm{g} / \mathrm{L}$ for Russian segment water.

Taken together, these constraints resulted in a design concept for a nontoxic TOCA to be deployed in a flightready package that considers microgravity flight and spacecraft cabin environmental conditions. This concept was developed through laboratory component-level testing, two moderate-fidelity integrated system breadboard prototypes, a flight-like full-scale prototype (the engineering development unit, (EDU)), and the final TOCA protoflight unit 1 (PFU1).

The TOCA layout consists of a custom-integrated chassis with an electronics and fluids module as shown in Error! Reference source not found.. When appropriate, commercial of-the-shelf (COTS) components were selected and integrated based on lessons learned during development. The electronics module contains power supplies, power distribution circuits, a computer, and a touchscreen interface. With the exception of wire feedthroughs, the fluids module is separate in terms of structure and chassis cooling. The fluids module chassis consists of front and rear compartments separated by a mid-plane bulkhead. Access to both compartments is made via large access panels which allow access to several components that are on-orbit replaceable units (ORUs) that require 
servicing throughout nominal operations (e.g., sample bag, acidic buffer container, waste bag, an oxidizer reactor, and a gasliquid-separator (GLS)).

Major elements of the TOCA schematic are shown in Figure 2. Several underlying core technologies of the analyzer, including the boron doped diamond (BDD)-coated electrode oxidizer, ${ }^{2,3}$ the volume compensation assembly (VCA), and the $\mathrm{CO}_{2}$ detector, ${ }^{4}$ were developed by OI Analytical of College Station, Texas. TOCA uses an innovative BDD-based electrolysis reaction to oxidize the organic carbon. It consists of two loops that perform the TOC analysis: a water sample loop and a gas loop. The water sample loop's primary function is to introduce and prepare the water sample for analysis. The sample loop contains valves and a pump to direct sample flow, a gas/liquid separator to remove gas from the water sample, a VCA to provide for sample loop volume adjustability as gas is eliminated (either by de-bubbling the initial sample draw or as TIC and TOC conversions are accomplished), an acid buffer solution container for TIC conversion, and an oxidizer reactor to oxidize TOC.

The gas loop requires the use of ISS nitrogen $\left(\mathrm{N}_{2}\right)$ as a sweep gas. It contains valves and orifices to control and direct gas flow,

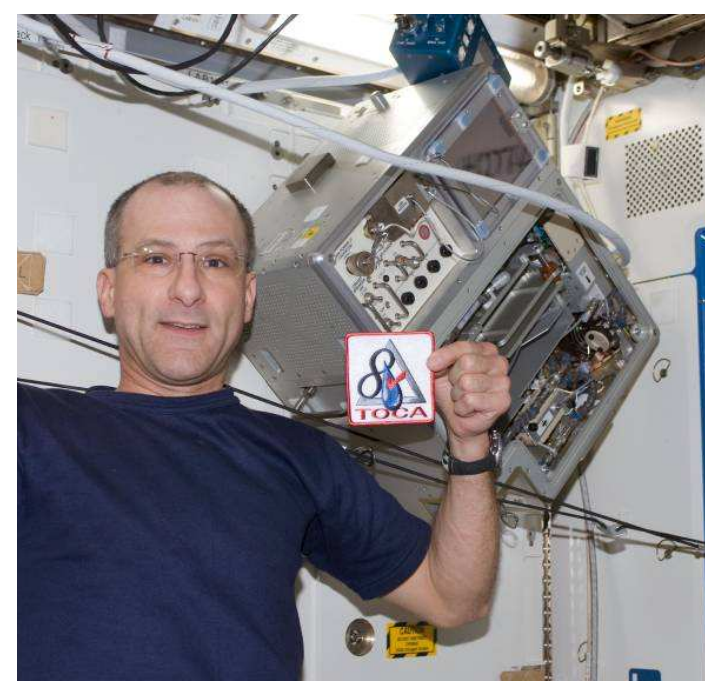

Figure 1. TOCA on the International Space Station with Astronaut Don Pettit prior to installation. Electronics module shown in top section, and fluids module with cover removed shown on bottom. an adsorber to remove residual $\mathrm{CO}_{2}$ from the ISS $\mathrm{N}_{2}$, a hydrogen $\left(\mathrm{H}_{2}\right)$ catalyst to reduce $\mathrm{H}_{2}$ and $\mathrm{O}_{2}$ by-products from the oxidizer's electrolysis process, a Nafion ${ }^{\circledR}$-tube-based moisture exchanger to remove moisture within the gas loop, and a nondispersive-infrared (ND-IR) detector to detect $\mathrm{CO}_{2}$ from TIC and TOC conversions.

A more in-depth review of the design of TOCA is discussed in a 2009 paper from this conference. ${ }^{5}$

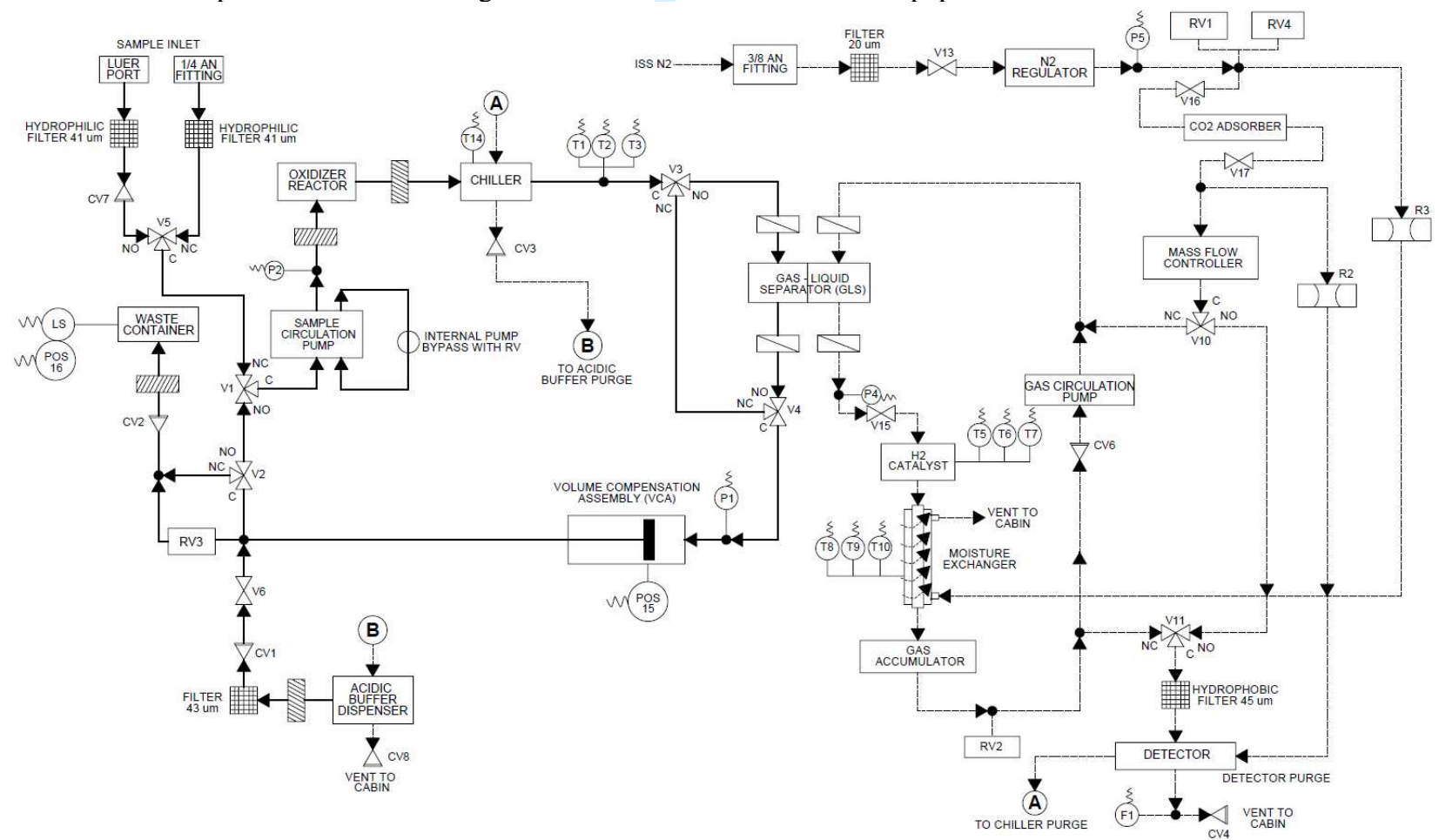

Figure 2. TOCA protoflight unit 1 (PFU1) process schematic.

\section{On-orbit Activation and Checkout Timeline}

The TOCA PFU1 arrived on the ISS in November 2008. The unit was installed in the ISS laboratory. Prior to being considered fully operational, both the WRS and TOCA had to demonstrate successful activation and checkout 
(A/CO), followed by successful 90-days of on-orbit operation. Requirements for the TOCA A/CO and 90-day checkout included the following:

- System "calibration check" values must be consistent with calibrated values.

- Review of engineering data must indicate that unit is operating as designed.

- Initial water sampling from the WPA had to be performed to ensure the TOCA sample values were consistent with archival sample values (ground-based analysis).

- Water sampling during a 90-day checkout period to ensure TOCA values matched archive sample analysis performed on the ground.

- Operate TOCA for a time period sufficient to require the waste bag ORU change out.

- Operate TOCA for a minimum of 12 analyses to verify no degradation of the GLS and provide overall trend data on the system.

The initial activation was performed on November 21, 2008, followed by a calibration check. The first analysis after checkout was terminated because of a GLS failure. It was repaired within 3 days by replacing the GLS, which is an ORU. The first waste bag change out was completed on December 3, 2008, meeting another 90-day checkout requirement. Before completing the last 90-day checkout requirement of completing 12 analyses, TOCA experienced an unexpected shutdown during analysis attributed to high pressure in the gas loop. Several troubleshooting runs were performed on orbit and in the TOCA engineering development unit (EDU) on the ground in an effort to identify the root cause of the problem. The engineering team determined that the $\mathrm{H}_{2}$ catalyst in the unit had stopped functioning and was allowing $\mathrm{H}_{2}$ and $\mathrm{O}_{2}$ gas to build up within the gas loop, causing early shutdown. An operational workaround was developed to allow continued operation of TOCA with the failed catalyst still in place. The "React TOC" phase of the analysis was reduced from 10 to 2 min to allow operation without exceeding the pressure limit, and the $\mathrm{H}_{2}$ and $\mathrm{O}_{2}$ generated during the run are now vented and dispersed into the cabin rather than using the TOCA catalyst to recombine the gases into water. Development of this process is described later in this paper.

Calibration of the new method was completed and subsequent analyses demonstrated good repeatability and no additional anomalies occurred during this period. A replacement catalyst and other repair items were delivered on flight $15 \mathrm{~A}$ as a contingency, but there are no plans to replace the catalyst given the success of the new method. Implementation of this new method allowed TOCA operation to continue, and the last operational requirement was met on March 4, 2009. TOCA operation was then deemed acceptable for a six-person crew on board the ISS.

\section{On-orbit Performance}

TOCA PFU1 was originally certified for a 1-year life but was extended to 2 years based on data obtained using the EDU on the ground. The following summarizes the on-orbit results and further discusses the on-orbit failures experienced to date.

\section{A. Analysis Results}

As of May 2010, TOCA PFU1 has completed over 125 analyses. An assessment of TOCA performance can be made by comparing in-flight results to two categories of ground-based analyses: (1) archived potable water samples analyzed in a laboratory after return to the ground, and (2) prepackaged on-orbit calibration standards.

The TOCA PFU1 meets analytical accuracy requirements of $\pm 25 \%$ within a range of 1,000 to $5,000 \mu \mathrm{g} / \mathrm{L}$ TOC. This range is required to envelope the go/no-go decision for water potability of 3,000 $\mu \mathrm{g} / \mathrm{L}$ for U.S. Segment potable water sources. When TOCA analyzes water above or below the calibrated values, it extrapolates a linear equation that increases error. The current TOCA instrument, as demonstrated by the in-flight data, tends to under-report values below $1,000 \mu \mathrm{g} / \mathrm{L}$. When the analytical response is exceedingly low, TOCA will calculate negative values for TOC.

A method detection limit (MDL) was calculated for TOCA per the procedure dictated by Environmental Protection Agency regulation 40 CFR Part 136, Appendix B. The MDL represents the minimum concentration that can be measured and reported with $99 \%$ confidence that the TOC concentration is greater than zero. As shown in Figure 3, the TOCA MDL was $200 \mu \mathrm{g} / \mathrm{L}$ from activation until January 2009, when it was increased to $475 \mu \mathrm{g} / \mathrm{L}$ because of the new analytical method developed in response to the hydrogen catalyst failure. Strict comparisons between in-flight and archive results are difficult since the majority of samples are below the TOCA MDL.

As shown in Figure 3, TOCA and archive results are in agreement that the ISS potable water is consistently well within the acceptable TOC range for crew health. More specifically, both data sets indicate the water is consistently below the minimum detection limit for TOCA $(475 \mu \mathrm{g} / \mathrm{L} \mathrm{TOC})$. A notable difference in the values is that the TOCA data are reporting negative values for TOC. This effect is caused by the limited calibration range of TOCA.

The TOCA preventative maintenance plan calls for analysis of a calibration check standard once every 3 months. The calibration check solution is nominally 3,000 $\mu \mathrm{g} / \mathrm{L}$ TOC to provide a test of instrument accuracy at the health limit.

4

American Institute of Aeronautics and Astronautics 
Figure 3 also shows results of five calibration checks that have been performed in-flight; all show good correlation with the ground-certified value. In addition, a 1,000 $\mu \mathrm{g} / \mathrm{L}$ TOC standard was analyzed on February 10, 2010, which again showed excellent correlation.

\section{B. Failures}

On November 23, 2008, a water sample analysis was automatically terminated due to off-nominal system health values. Review of the data indicated a potential leak in the internal water circulation loop or a lack of the system to fully prime and remove gas from the sample water. The crew was instructed to inspect for leakage and, following multiple troubleshooting activities over a 3-day period, found only a small droplet of water on the external housing of the GLS. The GLS is a replacement unit, so it was removed and replaced and subsequent TOCA analysis attempt was successful. The replacement GLS has performed without issue for over 15 months.

The leaking GLS was returned on space shuttle flight STS-126 for analysis and testing. Post-flight testing confirmed a leak on the water side of the failed GLS. Unfortunately, a root cause of the leak has not been determined, but no other in-flight or ground-based operations of the GLS assembly have produced similar failures, thus the failure seems isolated. Should future leakage occur at the GLS, this in-flight experience demonstrates the TOCA's capability for proper detection of an anomaly and simple in-flight replacement of the GLS unit.

On December 24, 2008, the TOCA automatically terminated an analysis by detecting high pressure in the gas loop during the "React TOC" phase. In an attempt to recover operations, the pressure limit was increased through an uplinked software change. The next analysis on December 30 was also terminated prior to completion due to high pressure in the gas loop. Initial root cause analysis revealed multiple potential causes. To provide more data, a troubleshooting activity was executed to dry the TOCA gas lines to evaluate moisture blockage as a potential cause of increased pressure; however, data collected during troubleshooting indicated no improvement in performance.

Subsequently, all legs of the fault tree were eliminated except for "catalyst failure", wherein the catalyst fails to recombine $\mathrm{H}_{2}$ and $\mathrm{O}_{2}$ gas products in the TOCA gas loop, which would allow accumulation of gases and result in increased pressure. The root cause of the catalyst failure cannot be determined without return and detailed analysis of the catalyst assembly. The catalyst assembly was not designed for on-orbit replacement; however, a spare catalyst was flown on STS-128 for in-flight maintenance in the event a software workaround was not possible. The resolution of this issue is described in the following section.

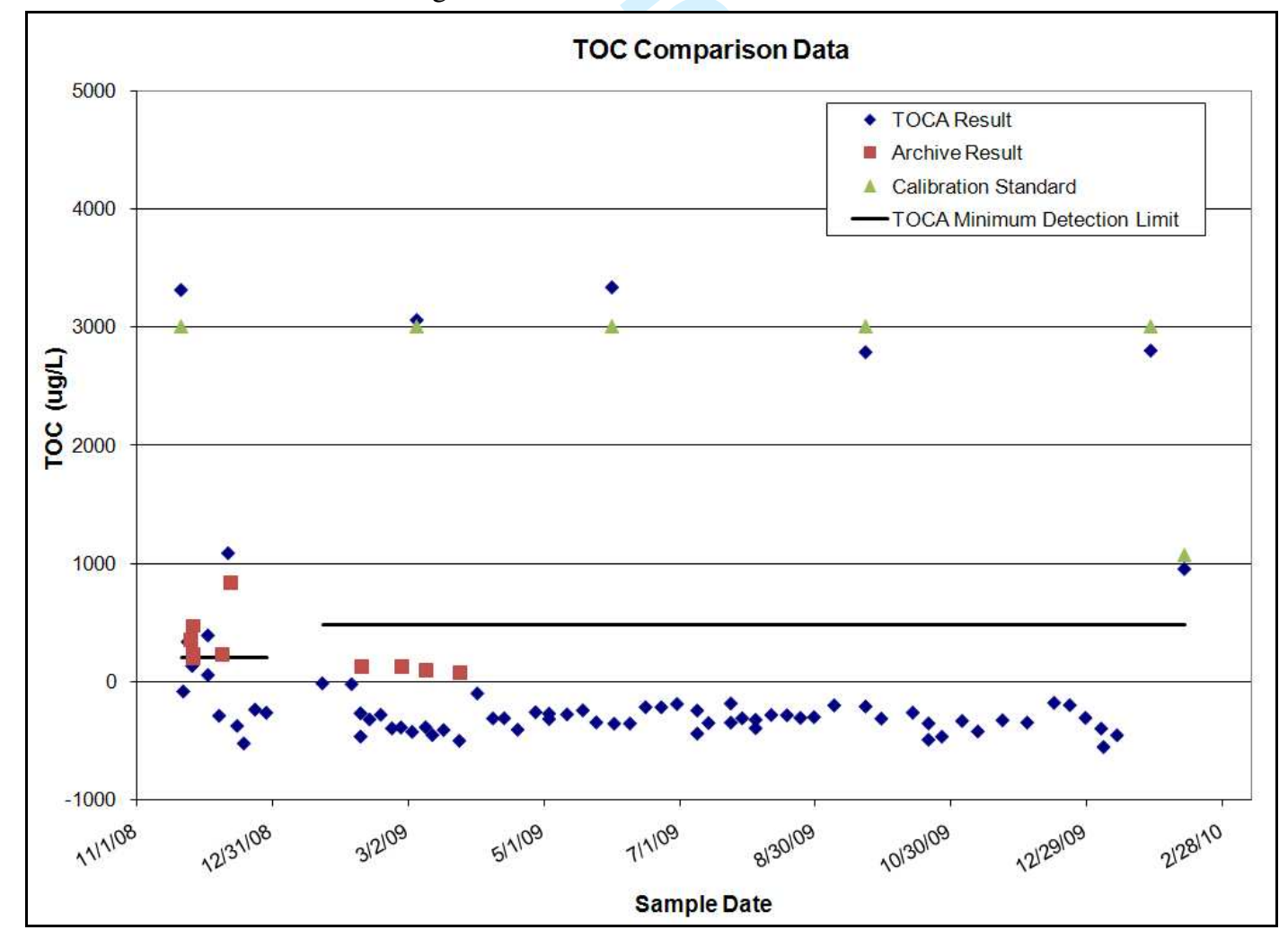

Figure 3. TOC analysis data for on-orbit TOCA results, comparison to archived samples analyzed on the ground, and given calibration standards. Negative values shown are because of poor TOCA accuracy at low TOC concentrations. Data is shown on chart to illustrate general trends with TOCA samples. 
In June 2009, a mass flow controller unit failed during ground-based testing. On power up, the valve within the mass flow controller failed to open and allow flow through the unit. The mass flow controller is used in the TOCA to precisely regulate the flow of $\mathrm{N}_{2}$ through the TOCA gas loop and $\mathrm{CO}_{2}$ detector. The $\mathrm{N}_{2}$ flow rate is directly related to $\mathrm{CO}_{2}$ detection and, therefore, is critical for accurate determination of TOC in water samples. Additional testing revealed other ground units were also failing to allow flow. Further inspection and discussion with the manufacturer indicated the internal valves could experience compression set if allowed to sit without being cycled for extended durations. Although the on-orbit mass flow controller component was functioning properly, a risk mitigation plan was initiated to ensure its regular cycling to minimize the risk of sticking. The plan requests operation of TOCA at least once every 14 days. This is typically not a planning constraint since the TOCA nominal operation schedule is to perform a water sample at least once per week.

On September 8, 2009, the in-flight TOCA pressure sensors detected off-nominal pressures resulting in an automatic termination of the sample analysis and the TOCA was powered down in a safe state. Evaluation of the downlinked pressure data confirmed that the liquid loop pressure exceeded the software-defined limits and terminated the analysis. The data also confirmed that the liquid loop relief valve opened and protected the system as designed. Other troubleshooting revealed the cause of the pressure increase to be a brief loss of VCA control due to temporary noise in the control lines. To date, this was an isolated occurrence of the anomaly, so it is confirmed as intermittent with a low recurrence frequency.

On October 20, 2009, the TOCA detected off-nominal high water temperature. Downlinked data confirmed agreement among all three sensors, and also indicated off-nominal high ambient temperatures at the start of analysis. Further investigation into the ISS cabin temperatures indicated that the cabin temperature was higher than experienced in any previous TOCA run. The TOCA water temperature is controlled by a thermoelectric chiller using feedback from thermistors T1, T2, and T3. Temperature control is necessary for TOCA because variability in water temperature impacts the accuracy of TOC analysis. TOCA thermal testing demonstrated that the TOCA chiller is limited, and ambient temperature variation can still impact water temperature and the TOC results. The high water temperature message has not repeated in any subsequent analysis. Should the nominal ISS temperature range change in future, the TOCA fault limits could be adjusted through a software update to avoid loss of analysis data.

\section{Hydrogen Catalyst Failure and Recovery}

As a result of the TOCA $\mathrm{H}_{2}$ catalyst failure, the TOCA no longer recombined $\mathrm{H}_{2}$ and $\mathrm{O}_{2}$, resulting in a gas buildup in the TOCA gas collection loop followed by automatic out-of-limit shutdown of the fault-detection program. The catalyst is not required for functionality but was implemented as a safety control. Safety impacts associated with this failure were a higher gas-collection loop pressure, a higher $\mathrm{H}_{2}$ concentration, and more $\mathrm{H}_{2}$ gas vented. To allow for continued TOCA operation without producing increased $\mathrm{H}_{2}$ safety issues, a 2-min oxidation process was adopted in place of a 10-min oxidation method. This lowered oxidization time reduced the gascollection loop pressure buildup, which is a key parameter in the $\mathrm{H}_{2}$ hazard analysis. The $\mathrm{H}_{2}$ vented is an insignificant amount.

Testing conducted on the ground using the TOCA EDU showed that while the TOC integrated area counts are significantly reduced with the 2versus 10-min approach, linearity and repeatability still exist. Data indicate that with this new method TOCA still meets performance requirements, primarily an accuracy of $\pm 25 \%$ for TOC levels from 1,000 to $5,000 \mu \mathrm{g} / \mathrm{L}$ with TIC levels up to $500 \mu \mathrm{g} / \mathrm{L}$ TOC (see Figure 4).

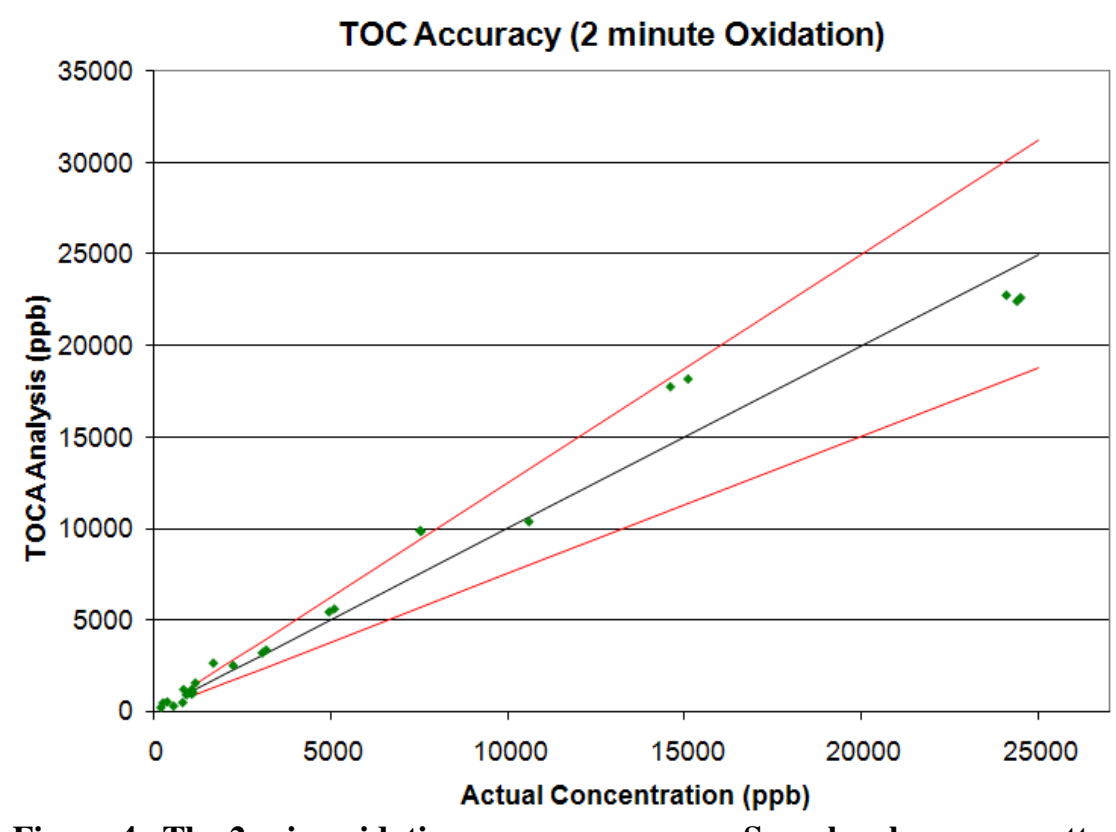

Figure 4. The 2-min oxidation process accuracy. Samples shown as scatter plot, with linear trend and statistical upper and lower bounds also shown for $25 \%$ accuracy $(\mu \mathrm{g} / \mathrm{L}=\mathrm{ppb})$.

6

American Institute of Aeronautics and Astronautics 


\section{Total Organic Carbon Analyzer Oxidation Efficiency}

The ISS TOCA uses a stable solution of potassium hydrogen phthalate (KHP) for certification testing and calibration. Early testing indicated that the TOCA was relatively insensitive to different compounds. Following the change of the TOCA process from 10 minute to 2 minute of oxidation time, TOCA was retested with a set of ISS-representative compounds. A sample preparation error produced a solution with a relatively high methanol concentration. When this solution was analyzed in the TOCA EDU, it over-reported this value relative to the commercial TOC analyzers used in the JSC Water and Food Analytical Laboratory (WAFAL).

The TOCA $\mathrm{CO}_{2}$ detector measures the by-product of oxidation $\left(\mathrm{CO}_{2}\right)$. Detector counts are integrated over time to produce a term called area counts that then is converted to TOC with a calibration curve. Plateaus were found to be high relative to KHP if the solution contained minimal carbon bonds. Large carbon chain molecules or multiple double-bonded carbons are known to be harder to oxidize, therefore producing less $\mathrm{CO}_{2}$ by-product until those chains were broken down. Several example compounds are shown in Figure 5.

To test the relative efficiencies of oxidation of these compounds and TOCA control parameters, the ratio of error relative to KHP counts was used. This assumes the KHP value for a given amount of TOC is correct and the TOC value, which is either lower or higher of another TOC species, is the error from that baseline. When this term is negative, the TOCA is under-reporting TOC; when it is positive, it is over-reporting TOC.

Data indicated that higher current density and increased time could reduce the effect of oxidation efficiency differences. The difficult compounds became the driving requirements that increased oxidizer current and time for subsequent TOCA iterations, as the easier compounds always completed oxidization earlier compared to KHP when oxidation time was extended. To approximate the values for current and time, the target area count error was set at $10 \%$ or less and solutions of $5,000 \mu \mathrm{g} / \mathrm{L}$ and $25,000 \mu \mathrm{g} / \mathrm{L}$ were analyzed. The target current and time were identified as $460 \mathrm{~mA}$ and $30 \mathrm{~min}$. The $460 \mathrm{~mA}$ was limited by the TOCA's 24-volt power supply and the resistivity of the oxidizer.

All the selections except the polysaccharides are considered compounds of toxicological concern that have been detected previously in some ISS archival potable water samples. Polysaccharides are large chain compounds and, thus, a good test of the number of carbons/carbon bonds hypothesis. Ibuprofen is a pharmaceutical that has 13 carbons (only one more carbon than sucrose). Benzene and caprolactam both have six carbons, so using both would test the benzene ring effect; however, benzene is very volatile and could confound data interpretation. Formaldehyde was selected over ethylene glycol as a small compound for comparison to methanol because formaldehyde is the limiting compound for the TOC drinking water limit of 3,000 $\mu \mathrm{g} / \mathrm{L}$.

Representative TOCA oxidation efficiency results are shown in Figure 6, indicating effective and accurate oxidation for the range of organic carbon constituents tested. This new oxidation method will be implemented on future TOCA flight units.

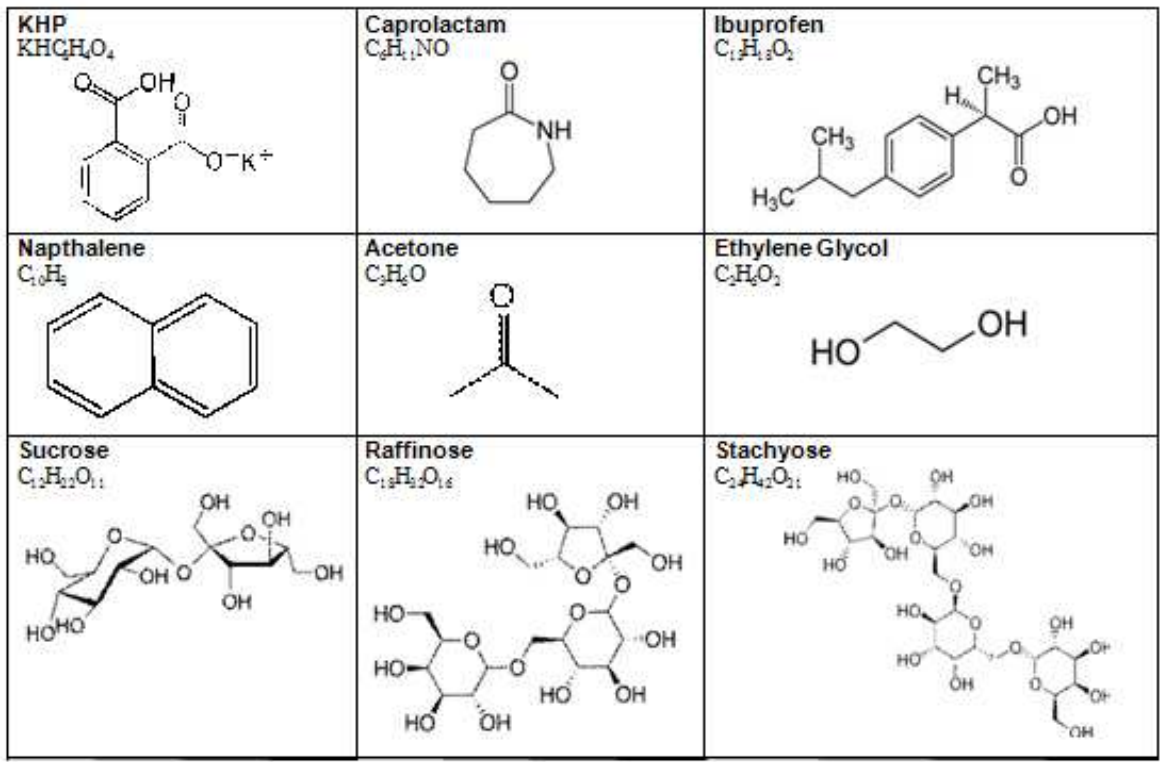

Figure 5. Example organic carbon compounds tested in TOCA.

American Institute of Aeronautics and Astronautics 


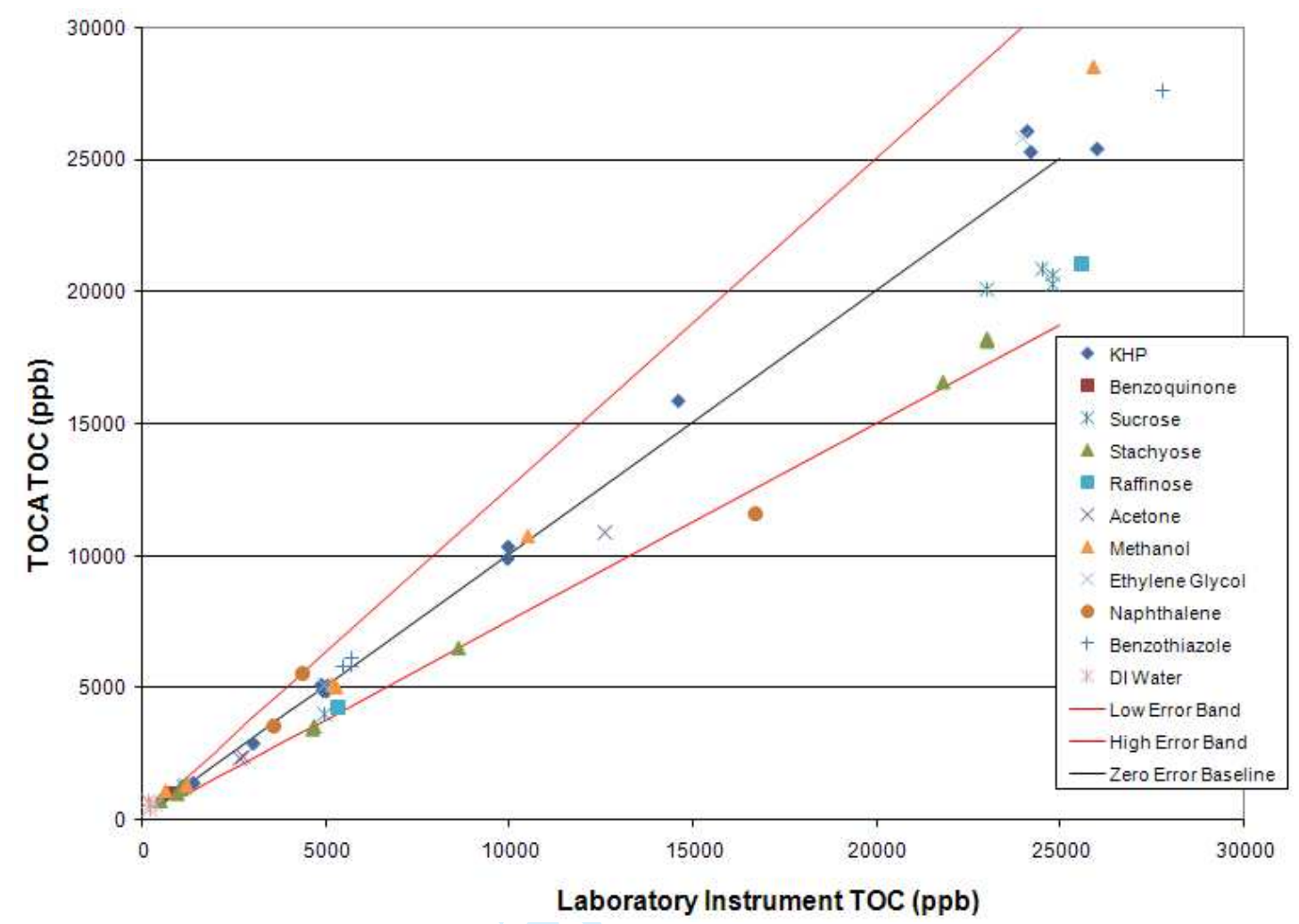

Figure 6. Representative TOCA oxidation efficiency results with a range of tested constituents for $460 \mathrm{~mA}$ and 30 minute oxidation time $(\mu \mathrm{g} / \mathrm{L}=\mathrm{ppb})$.

\section{Further Development and Recommendations}

To meet the required delivery timeline, operational requirements for PFU1 were reduced from the original set of requirements. Two more TOCA protoflight units are being built (PFU2 and PFU3) to support on-orbit sampling of reclaimed water for the life of the ISS. These two units will meet the original requirements and will have longer life, design and operational improvements over the original flight unit. Design improvements are based on experience with the first flight unit (PFU1). Requirements for PFU2 and PFU3 will enhance accuracy and range performance of TOCA, add the capability to analyze water from Russian segment sources on orbit, and certify life to 5 years. The difference in performance requirements for TIC and TOC detection between PFU1 and PFU2/3 are shown in Figure 7.

Electronics improvements are being made to the power system to reduce the TOCA susceptibility to power transients and to improve power distribution throughout the TOCA electronics module. Changes recommended in a government-industry data exchange program (GIDEP) alert for a voltage reference that is used at multiple locations in the TOCA electronics will also be implemented.

Mechanical improvements include a redesign of the oxidizer cable to be more user-friendly and add strain relief. The oxidizer is an ORU that requires the ability to mate/de-mate the cable numerous times without damage. $\mathrm{TheH}_{2}$ catalyst function is also being removed, and the routing for the gases produced during analysis is being reworked to allow all gases to be diluted with $\mathrm{N}_{2}$ flow prior to venting into the cabin.

Some technology improvements are also being made, one to incorporate a redundant infrared (IR) filament in the TOCA detector to increase reliability, and one to add a second universal serial bus (USB) port for keyboard/mouse control of TOCA. The next two flight units are also adding the capability to be controlled wirelessly if this functionality should be desired in the future. 


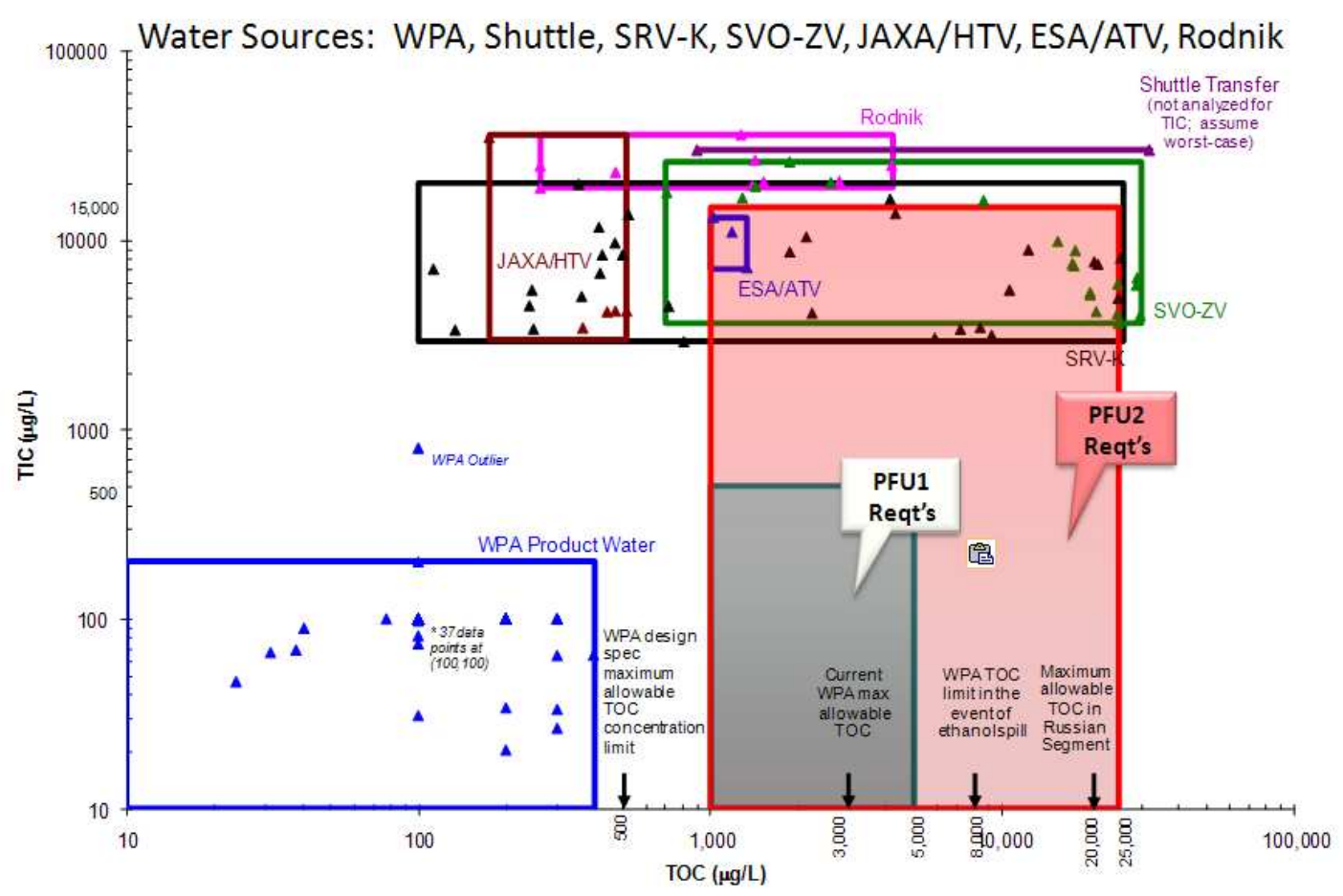

Figure 7. Range of expected TOC and TIC contaminants in various water sources on the ISS; PFU1 vs. PFU2 requirements.

Beyond the development of PFU2 and PFU3, several other lessons can be learned that may improve similar technology in the future. Continued development of TOCA systems is treated here as a potential set of redesign opportunities for TOCA-like systems that would serve potential needs of ongoing ISS and future human space flight programs. We consider this a brief advance planning exercise to explore development approaches for future TOCA systems.

The TOCA protoflight units (PFU1, PFU2, and PFU3) serve as a well-defined baseline of a flight-rated TOCA system. Other potential redesign opportunities with respect to this baseline system consider four basic classes of development strategies, as shown in Table 1. These development options, which serve as a framework for future trade studies, are useful for human space flight stakeholders to consider when generating plans for future projects.

Table 1. General recommendations for further development of TOCA-like systems

\begin{tabular}{|c|c|}
\hline $\begin{array}{l}\text { Development } \\
\text { Strategy }\end{array}$ & Engineering Approach \\
\hline More Robust & $\begin{array}{l}\text { Perform more exhaustive characterization of the TOCA } \\
\text { system to identify sensitivities and define performance } \\
\text { limits }\end{array}$ \\
\hline More Effective & $\begin{array}{l}\text { Conduct studies to determine process methods that } \\
\text { will oxidize a larger set of challenge solutions }\end{array}$ \\
\hline More Efficient & $\begin{array}{l}\text { Perform parametric exercises to identify more optimal } \\
\text { design solutions for the same nominal requirement set }\end{array}$ \\
\hline $\begin{array}{l}\text { More } \\
\text { Innovative }\end{array}$ & $\begin{array}{l}\text { Systematically identify and perform feasibility analyses } \\
\text { of TOCA variants along the following perspectives: } \\
\text { Functionality } \\
\text { Architecture } \\
\text { Interfaces } \\
\text { User interactions }\end{array}$ \\
\hline
\end{tabular}

More durable Longer life rating Improved environmental operating capability Increased capability of monitoring broader range of samples and contaminants Smaller Lighter Less power, water, and time to operate Use oxidation to treat water, not just monitor water quality (TOCA recycler) Perform real-time quality measurements during water recycling (TOCA within WPA) Radically different system layout and packaging (TOCA in a can or as part of the drinking dispenser) 


\section{Conclusion}

The second-generation TOCA has been on the ISS for over 11/2 years, and has served as a valuable and reliable tool for analysis of WPA potable water. TOCA results correlate well to archived ground-analyzed samples and calibration check standards.

Several failures and other issues during checkout and operational use of TOCA were resolved, and provided able valuable design information for further improvements to subsequent TOCA units. In particular, an improved oxidation method was developed that precluded the need for an $\mathrm{H}_{2}$ catalyst, yet resulted in data within accuracy requirements.

The TOCA PFU1 has demonstrated the viability of a reagent-free, autonomous analytical instrument for microgravity space flight, and lends credibility to the continued development of similar instruments.

\section{Acknowledgments}

The authors recognize and thank the dedication and skill of the TOCA team, including Bioastronautics contract personnel project manager Steve Maignaud, deputy project manager Jeff Milstead, John Shultz, John Straub, Eric Warren, Mike Romell, Daniela Monterrubio, Heather Mera, Gary Jones, Ben Shoemaker, Scott Flechsig, and Alan Ruter. At NASA, Dr. Karen Pickering, Nik Adam, Carolyn Krumrey, Dale Roberts, and Dave Mathers provided guidance.

\section{References}

1. Straub, J., et al., ISS Total Organic Carbon Analyzer Status Update- 2003, in International Conference on Environmental Systems 2003, SAE: Vancouver, BC.

2. Kounaves, S., Total Organic Carbon (TOC) Analyzer, US20050226774A1, USPTO. 2005: USA.

3. Erickson, G. and K. Williams, Total Organic Carbon Analysis, US20070183929A1, USPTO. 2007: USA.

4. Rawls, N., A. Solar, and K. Morris, Non-Dispersive Electromagnetic Radiation Detector, PCT/US2008/052109, USPTO. 2008: USA.

5. Clements, A., R. Stinson, and E. Warren, Development of the Second Generation International Space Station (ISS) Total Organic Carbon Analyzer (TOCA) in International Conference on Environmental Systems (ICES)2009, SAE: Savannah, GA.

6. Saunders, M., C. Seepersad, and K. Holtta-Otto, The Characteristics of Innovative, Mechanical Products, in ASME International Design Engineering Technical Conference2009, ASME: San Diego, CA. 